Article

\title{
Forty Years' Experience in Teaching Fluid Mechanics at Strasbourg University
}

\author{
Daniel G. F. Huilier (D)
}

ICUBE laboratory-CNRS, Faculty of Physics \& Engineering, Strasbourg University, 67084 Strasbourg, France; huilier@unistra.fr; Tel.: +33-637597063

Received: 8 November 2019; Accepted: 27 November 2019; Published: 29 November 2019

\begin{abstract}
A summary of the personal investment in teaching fluid mechanics over 40 years in a French university is presented. Learning and Teaching Science and Engineering has never been easy, and in recent years it has become a crucial challenge for curriculum developers and teaching staff to offer attractive courses and optimized assessments. One objective is to ensure that students acquire competitive skills in higher science education that enable them to compete in the employment market, as the mechanical field is a privileged sector in industry. During the last decade, classical learning and teaching methods have been coupled with hands-on practice for future schoolteachers in a specific course on subjects including fluid mechanics. The hands-on/minds-on/hearts-on approach has demonstrated its effectiveness in training primary school teachers, and fluids are certainly a nice source of motivation for pupils in science learning. In mechanical engineering, for undergraduate and graduate students, the development of teaching material and the learning and teaching experience covers up to 40 years, mostly on fluid dynamics and related topics. Two periods are identified, those prior to and after the Bologna Process. Most recently, teaching instruction has focused on the Fluid Mechanics Concept Inventory (FMCI). This inventory has been recently introduced in France, with some modifications, and remedial tools have been developed and are proposed to students to remove misconceptions and misunderstandings of key concepts in fluid mechanics. The FMCI has yet to be tested in French higher education institutions, as are the innovative teaching methods that are emerging in fluid mechanics.
\end{abstract}

Keywords: fluid mechanics; science teaching; hands-on/minds-on/hearts-on; inquiry-based problem; science learning; educational activities; FMCI; Strasbourg University

\section{Introduction}

The present paper summarizes a 40 year learning and teaching experience in a French university, with the occasional assistance of foreign professors on sabbatical and on-the-job learning that took place in the mid-1970s. Teaching fluid mechanics-connected to mathematics, computer science, and numerical methods-is summarized for undergraduate and graduate students in mechanical engineering. However, over the last 15 years, learning how fluids behave based on hands-on methods was also shown to be a challenge for future school professors [1]. Details on this specific teaching activity will be developed in Section 2. Critical aspects related to drastic changes in the curricula, often a consequence of the Bologna Process [2,3], are also highlighted in fluid mechanics engineering. The development of computer science, the internet, and innovative pedagogical methods in learning and teaching science (SoTL, [4]) will bring to light that novel methods are needed to persuade students to pursue the subject of fluids in their studies in higher science education, as well as to improve young people's interest in science studies and attract them to fluid mechanical engineering and related professions. A recent proposal, presently tested on a remediation program, to fill in the gaps and deficits in fluid mechanics will also be developed; this is inspired by the Fluid Mechanics Concept 
Inquiry (FMCI) test initiated by Martin, Mitchell, and Newell [5,6]. The first part of this paper is devoted to the teacher training that started in 2007, a rather unusual investment for an academic scientist specialized in physics and fluid mechanics. The experience of teaching fluid mechanics in an engineering faculty, at undergraduate and graduate levels, is described in the second part, which is subdivided into Sections 3 and 4, teaching prior to and after the implementation of the Bologna Process. This part concerns the main activity of the author's career. Section 5 focuses on the tools being developed to improve teaching and learning fluid mechanics in regard to overcoming students' misconceptions with help of the FMCI, remediation tools, and the acquired experience in educational sciences. A short review of recent innovative teaching and learning methods applied to fluids completes the paper, with the goal of encouraging collaboration with young colleagues.

\section{Teaching and Learning Fluids with Future Schoolteachers}

Undergraduate students willing to become primary schoolteachers in France must complete a Master's in Education Science and succeed in a competitive exam. One option suited to students in biology, life science, chemistry, engineering or physics is to follow a course entitled "Experimenting and Understanding Physical Sciences", which was founded 15 years ago. It is based on the hands-on/minds-on method coupled with constructivism, science learning, inquiry-based problems, hypothetico-deductive (HD) reasoning, methods of observation, initial representation, verification by experimentation, and feedback. The group asserts that a change in school science teaching pedagogy from mainly deductive to inquiry-based methods will provide the means to increase interest in science. Indeed, the "learning by doing method", in which the teacher accompanies the pupil and leads him to discover science for him/herself, stimulates the child's observation skills, imagination, and reasoning capacity [7]. The course unit consists of four lectures, mainly via an introduction to Education Science and different scientific investigation approaches (hands-on, inquiry-based, problem-based, inductive, deductive, and HD processes). The course is further organized into five practical sessions in physics and chemistry (among one in Newtonian and fluid mechanics); The required education level of scientific knowledge being the third year of the Batchelor's Degree. The students learn to apply the HD and hands-on during these sessions, last they learn to create lesson cards for elementary classrooms at home. Preference is given to educational science as proposed by Marguerite Altet, Jean-Pierre Astolfi, Philippe Meirieu, Philippe Perrenoud, and Michel Serres.

Hands-on [1] was introduced in France by Georges Charpak (Nobel prize, 1992) after visiting schools in Chicago, where he met Leon Lederman (Nobel prize, 1988) and Karen Worth, the daughter of physicist Victor Weisskopf. Karen Worth is an important figure in the development of inquiry-based and hands-on learning in schools. They also worked with Jerry Pine at Caltech, who successfully developed a K-12 systemic reform of science learning and inquiry-based science teaching with the hands-on experimentation model. Jerry Pine pioneered this model by offering experimental kits to his students [8].

\subsection{Hypothetico-Deductive (H-D) Method in Sciences}

The hypothetico-deductive (H-D) method, broadly used in science research, is classically a seven-step process (according to Popper [9-11] and further contributions [12,13]):

- Identify a broad problem area;

- Define the problem statement;

- Develop hypotheses;

- Determine measures;

- Data collection;

- Data analysis.

In our case, we slightly modified the different steps of the scientific investigation method, associating theory with experimentation (Figure 1). For a given problem (experiment to be carried out, 
evocation/display of a phenomenon, of a technical object, scientific question) related to an available theoretical structure (model, concept, knowledge), we present the following items:

- Observation and questioning related to initial representations, problem identification;

- Theoretical framework, background research, preliminary information gathering;

- Elaboration of hypotheses (testable, falsifiable afterwards);

- Definition, design of test experiments;

- Predictions of results associated to the test experiences;

- Experimentation, data recording and collection, and analysis/interpretation;

- Validation or invalidation of hypotheses and predictions, as well as their assessment;

- Elaboration of a theory or law based on robust validations.

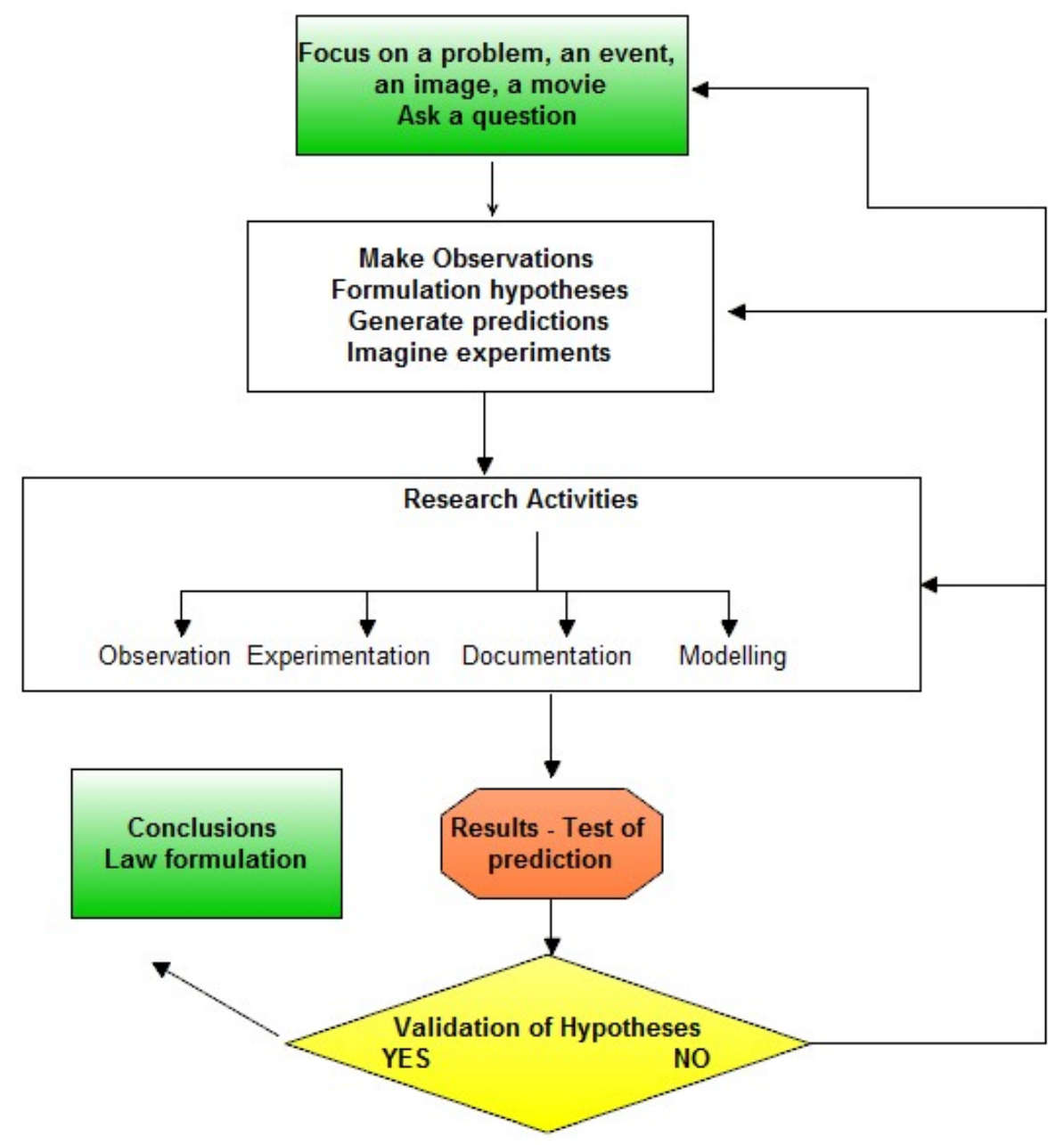

Figure 1. Schematic of the scientific method.

\subsection{Practical Work and Projects in Fluid Mechanics}

In fluid mechanics, the students, except for the last item on lesson cards, must provide a quality work at a Bachelor's degree, and they:

$>$ Have two weeks to update their knowledge in fluids (Newton's laws, free fall bodies in a void, fall in air or water/oil, the Archimedes' principle, the Bernoulli law of perfect fluids) and investigate the concepts of viscosity and drag force (Reynolds number, Stokes' law, terminal fall velocity), writing all in a science notebook. 
$>$ Must imagine simple inexpensive experiments that identify and highlight relevant science notions and concepts, with some available material being listed and some experience items being proposed, such as:

- Galileo's experiments of falling objects, using sport balls in air from different heights up to $20 \mathrm{~m}$ (to observe differences in terminal velocities for different spheres (diameters, density));

- Making a classic Cartesian diver (understanding pressure, Archimedean buoyancy);

- Building a parachute with fabric and string/building a wind turbine;

- Observing the settling of sand grains in water;

- Observing bubbles rising in oil or water, or the fall of a golf ball in water (viscosity calculation);

- Galileo's experiment with rolling balls down an inclined plane (the calculation of gravity);

- The levitation of a ping pong ball (Coanda effect, Bernoulli equation);

- The measurement of the density of objects (cork, lead sinkers) based on the Archimedes' principle.

$>$ Investigate and execute creative experiments while setting up the hypothetico-deductive teaching strategies.

$>$ Elaborate several lesson preparation cards for pupils in primary schools on a topic related to fluid mechanics.

Aside from the available materials, students can use computer and web resources, textbooks and lecture notes, scientific articles, exercises, and educational videos, which are made available on a personal website [14], to prepare their practical work and experiments during their practical session. The course is intended to develop skills in fluid mechanics as well as in science education. The benefits of the course include:

- Improvement in organization of their working hours;

- Efficient use of available information and resources (in books, articles, the internet);

- Investment and teamwork (organizing small students' groups for interactive pedagogy learning);

- Scientific curiosity, creativity, motivation, and the pleasure of learning;

- Acquisition of reflective practice and scientific questioning;

- Implementing the HD method coupled with a project-based approach;

- Problem solving, formulating and testing hypotheses, theories, or laws;

- Analyzing and understanding scientific phenomena;

- Learning to measure and calculate with efficiency;

- Developing various abilities and skills, including the acquisition of transversal competences such as creativity and critical thinking.

\subsubsection{Example of an Experiment: Free Fall of Bodies}

The present example is dedicated to the laws governing falling bodies in a vacuum, gas, or liquid. Students have to imagine experiments such that highlight the different forces acting on a falling body (gravitational force, buoyancy, drag/air or liquid resistance). Several text extracts such as passages from the Principia, popular and scholarly articles, and some handouts on Newtonian mechanics help them to recall Newton's laws of motion. In a vacuum-as on the moon, in the absence of an atmosphere-all objects fall at the same rate, as astronaut Dave Scott demonstrated by dropping a hammer and a feather in the Apollo mission XV in 1971. This experiment, shown in NASA or Youtube videos [15], can help students to understand Newton's second law of motion in a vacuum.

Without any other force besides gravitation, and air resistance being neglected, in Earth's atmosphere, spheres dropped at zero speed, have a velocity $V$ and impact time $T$, as given in Table 1 . Although simplified, Table 1 yields an order of magnitude of $T$ and highlights the difficulties in making observations with only a chronometer and a measuring tape for small values of $T$. Furthermore, 
students would be interested and excited to experience the simultaneous fall of different spheres from the third or fourth floor of a university building, just like the Galileo's hypothetical Leaning Tower of Pisa experiment.

Table 1. Time and velocity reached in free fall from different heights.

\begin{tabular}{ccc}
\hline Height (in meters) & $\boldsymbol{T}=(\mathbf{2} \mathbf{h} / \mathbf{g})^{\mathbf{1 / 2}}(\mathbf{s})$ & $V(\mathbf{m} / \mathbf{s})=\mathbf{g} \boldsymbol{T}$ \\
\hline 1 & 0.45 & 4.4 \\
2 & 0.64 & 6.3 \\
3 & 0.78 & 7.6 \\
5 & 1 & 9.8 \\
10 & 1.43 & 14 \\
\hline
\end{tabular}

A rain droplet has a fall velocity of about $10 \mathrm{~m} / \mathrm{s}$ [16]. Students have to investigate the reasons behind this value and become familiar with the concept of air resistance inducing a drag force that increases with velocity, as well as the concept of terminal velocity of bodies falling in fluids. Supplementary papers or textbook chapters are made available to students on drag, sport ball ballistics, and the famous Reynolds number as well [17-20]. Many spheres of different sizes and material composition (golf balls, tennis balls, table tennis balls, baseballs, whiffle balls; plastic, rubber, glass, or metal balls; hollow balls) are available to students to experience the dynamics of falling bodies (Figure 2). As potential distractors, other objects are usually added to the panel (a badminton shuttlecock, a crumpled sheet of paper, hollow balls with many holes, etc.).

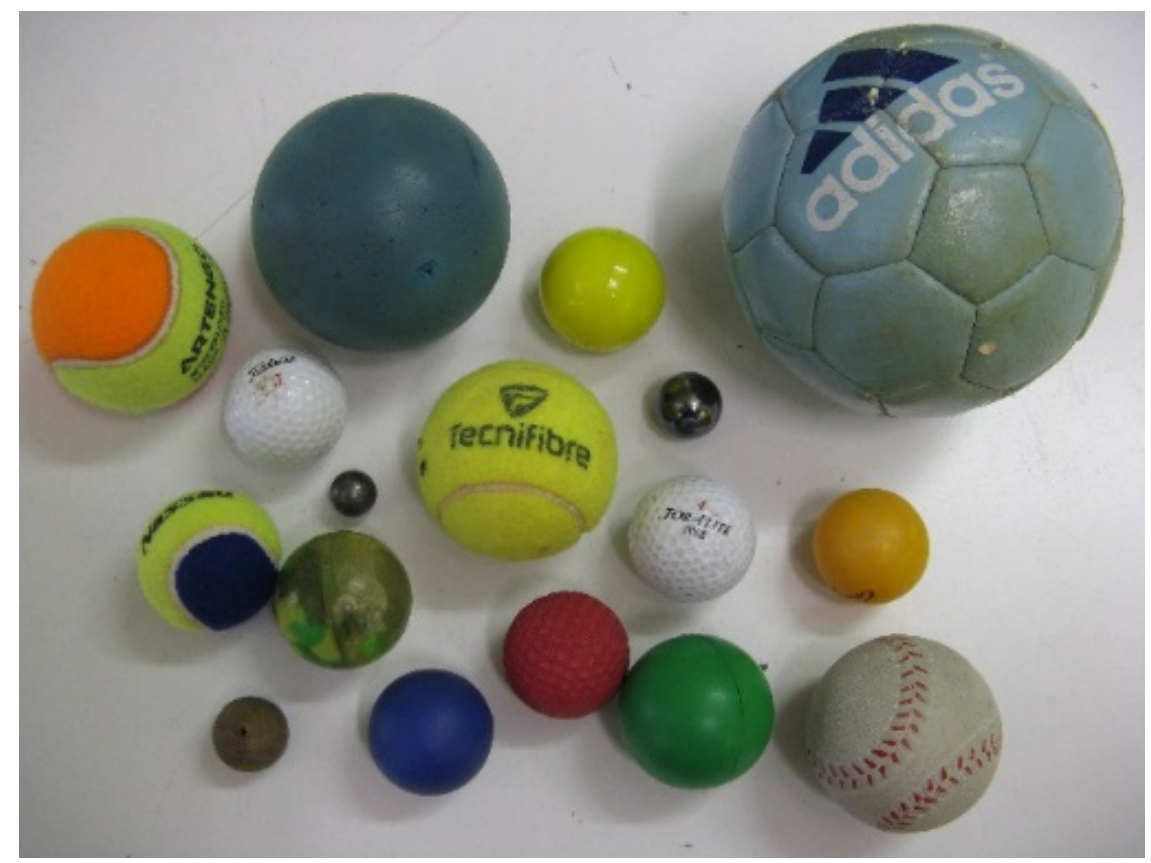

Figure 2. Set of sport balls and other spheres.

For most spheres and sport balls, released from less than $5 \mathrm{~m}$ in air, gravity is the only force acting on them. Some distractors do not really behave differently. However, by releasing spheres from at least $15 \mathrm{~m}$ outside a building, students begin to notice a difference. They nevertheless have some doubt about the nature of the other forces acting on the spheres, Archimedes' buoyancy or drag forces due. revealing misconceptions of surface forces, pressure, viscosity, and viscous effects. Complementary experiments in water, 'does it sink or float', the levitation of a ping pong ball with a hair dryer, are essential to deepen the students' understanding of the different observed phenomena. It is the teacher's role as mediator and facilitator to provide explanations and clarifications on the 
nature of these other forces. Once Newton's second law of motion is well written, calculations can be then made to determine atmospheric or hydrodynamic drag force, the coefficient of drag for the object, the instantaneous or terminal velocity of the object.

The bouncing of balls on different surfaces (ceramics, natural stone, concrete, parquet or laminate, sand, etc.) can also be analyzed, and the effect of various drop heights on the bounce height of a ball can be studied [21-23].

\subsubsection{Example of an Experiment: Viscosity Calculation}

Small air bubbles released from the bottom of a vertical tube of water or oil reach their terminal velocity in a quite short distance. By measuring the time elapsed from a given height, the terminal velocity can be easily calculated; supposing the viscosity of water or oil is unknown Newton's second law of motion states that the equilibrium of the external forces on a bubble (weight, buoyancy, and drag) enables the estimation of the viscosity. The only cautions are that bubbles remain spherical, which is a good approximation for diameters less than $0.5 \mathrm{~mm}$. Furthermore, Stokes' law (at small Reynolds number (Re)) is justified. For larger bubbles, other drag coefficient laws such as that of Schiller-Naumann [24] can be applied, though trial-and-error or iterative calculations are needed to obtain the viscosity. By solving Newton's law, the terminal velocity $U$ is given by

$$
U=\sqrt{\frac{4}{3} g \frac{D}{C_{D}(\operatorname{Re})}\left(\frac{\rho_{p}}{\rho_{f}}-1\right)}
$$

where $D$ is the sphere diameter, $\rho_{f}$ and $\rho_{p}$ are the fluid and sphere bulk density (volume weight), and $C_{D}$ is the drag coefficient as function of the Reynolds number Re. The derived equation for $U$ is nevertheless implicit since the drag coefficient $C_{D}$ is itself a function of $U$.

Starting with the equation of the motion of a sphere under gravity, the buoyancy and drag of a fluid at rest can be determined as

$$
\rho_{p} \pi \frac{D^{3}}{6} \frac{d u_{P}}{d t}=\pi \frac{D^{3}}{6}\left(\rho_{p}-\rho_{f}\right) g-\pi \frac{D^{2}}{8} \rho_{f} C_{D}(\operatorname{Re})\left|u_{P}\right| u_{P}
$$

At equilibrium, it is

$$
\pi \frac{D^{3}}{6}\left(\rho_{p}-\rho_{f}\right) g=\pi \frac{D^{2}}{8} \rho_{f} C_{D}(\operatorname{Re})|U| U
$$

In the case of Stokes' drag, $C_{D}=24 / \mathrm{Re}$, the drag force is reduced to $F=3 \pi \mu D U$, the terminal velocity is given by $U=\frac{g D^{2}}{18 \mu}\left(\rho_{p}-\rho_{f}\right)$, and the dynamic viscosity is $\mu=\frac{g D^{2}}{18 U}\left(\rho_{p}-\rho_{f}\right)$. The Stokes' relaxation time is $\tau_{P}=\frac{\rho_{P} D^{2}}{18 \mu}$, after which a falling sphere reaches $63 \%$ of its maximal velocity. Other possible experiments could be the measurement of the viscosity of milk [25] or water-for this experiment, it is best to choose a small sphere with a bulk density close to that of the fluid. The sedimentation/settling of sand grains in water can be an attractive activity too, wherein the settling velocity measurements and water viscosity allows the calculation of the diameter of the sand grains, for instance.

\subsubsection{Some Scientific Questions Treated in a Preparation Sheet}

A preparation sheet is school lesson plan, created by the teacher, involving the learning objectives of the lesson, step-by-step experiments and activities for the pupils, and details of the materials to be used and possibly what should be written in child's notebook. It may involve a formative assessment. It must be in concordance with the curricula fixed by the French Ministry of National Education. When well written, it can allow a colleague to step in and lead the planned lesson in the event of absence or disease. 
Preparing a sheet on a subject related to fluid mechanics for an elementary classroom is a difficult task. It is very time-consuming, requires imagination and skill, and requires inexpensive materials for experiments to be conducted by several groups of three to four children. These preparation sheets are intended for primary classrooms. The concepts and vocabulary must be popularized and adapted to the age of the children to be taught, which represents a real challenge for novice teachers. The teacher's role as facilitator is important for this task and time consuming for both parties, learner, and mediator. Here the learning cycle, play (heart-on learning), explore (hands-on Learning), and discuss (minds-on) is crucial.

Aside from their well-known textbook in physical hydrodynamics [26], Etienne Guyon et al. published a popularizing science book on fluids (unfortunately only available in French) entitled What Fluids Tell Us [27]. This textbook contains a vast selection of real-world, engaging examples of fluid mechanics, such as the falling of snowflakes and bubbles in a champagne glass, which are invaluable for novice teachers when writing their lesson plans. Another French textbook, now available in English, illustrates the wonder of fluids through "drops, bubbles, pearls, and waves" [28].

\section{Teaching Fluid Mechanics from 1976 to 2002}

From early period (1976) to the Bologna Process, teaching fluid mechanics to undergraduate and graduate students was quite well established. The library resources were reduced to some lecture notes and to a few fundamental books. For undergraduate students, most of the topics were covered in French books or in a few available English books (from Curle-Davies, Shapiro, Anderson, White, etc.). For graduates, classical books (such those of Batchelor, Hinze, Schlichting [29-32] or Lumley, Monin-Yaglom, Chandrasekhar, etc.) and the Journal of Fluid Mechanics, as well as the scientific papers of G.I. Taylor and microfilm issues, provided support for the teaching of fluid mechanics and turbulence. A large allocated volume of teaching hours and well-equipped laboratory experiments using pressure-velocity measurement techniques (Pitot, hot-wire, and even laser anemometry) favored extensive learning in fluids.

The advent of microcomputers fostered computational fluid dynamics, and the internet brought about the creation of effective websites. Besides a myriad of new textbooks, very serious scientific websites delivering much material on homework, courses, handouts, and exercises with corrections could be used for the content of a curriculum on fluid mechanics. Furthermore, enough teaching time was still allocated to enable in-depth training in many fields (statics of fluids, kinematics, dynamics, ideal fluids, viscous flows, internal and external flows, incompressible or compressible, turbulence, two-phase flows). The curriculum was coupled with numerical methods, applied mathematics, and computer science. The onset of turbulence, chaos, non-linear phenomena, and hydrodynamic instabilities appeared around 1990 and these courses, although a challenge for university professors, found a broad audience among students. It should be noted that undergraduate students had a solid background and skills in mathematics and physics, and master students were able to easily assess/handle partial differential equations (Navier-Stokes equations). Moreover, neither laminar/turbulent boundary layer theories (Blasius, Falkner-Skan, von Karman equation, Polhausen, or Twaites methods), plane or

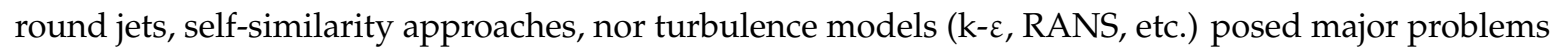
to most of these students. Learning to apply finite difference or finite volume techniques as well as remeshing and studying stability problems of numerical schemes also found enthusiastic participation.

\section{Teaching and Learning Fluids after the Bologna Process}

The Bologna Process [2,3] is an intergovernmental higher education reform and cooperation process, launched in 1998 (Sorbonne declaration)-1999 (Bologna declaration). Its principal purpose is to promote the quality and recognition of the higher education systems in 48 European countries and to implement a common degree level system for undergraduates (Bachelor's degree) and graduates (Master's and Doctoral degrees), based on the so-called European Credits Transfer and Accumulation System (ECTS). In addition, it aims to facilitate student and teacher mobility, increase the recognition 
of academic degrees and qualifications, and increase employability, enhancing the attractiveness of in higher education in Europe. A number of European organizations (UNESCO, Council of Europe, ENQA, EUA, etc.) are also involved in this reform. The European Higher Education Area (EHEA) was launched in 2010 at the ministerial summit in Budapest, Vienna.

Several studies and recent reports based on TIMSS (Trends in Mathematics and Science Study) have shown that in France, the educational achievements of 15-year-olds and the share of high school students that go on to university are now below the EU average. They are lacking mathematics and science abilities. Since the Bologna process started twenty years ago, the French government and the Ministry of National Education modified several times all the curricula in primary and secondary schools, reducing the training hours allocated to science, engineering, and mathematics. Very recently the "Baccalauréat", the French secondary school diploma/ high-school degree (A-levels in UK) curricula again. Furthermore, the best high school pupils often opt for non-scientific disciplines and young people turn their backs on science. The progressive changes in European higher education led all French universities and some engineering schools to reconsider the programs and curricula on a national level and to revisit the contents and objectives of undergraduate and graduate programs, especially in STEM (Science, Technology, Engineering, and Mathematics). As a consequence, Bachelor of Science programs were affected and modified, and changes are still underway, at least in the French universities. These are some real causative factors for the observed changes in student ability in science and technology.

The progressive changes in European higher education led all French universities and engineering schools to reconsider the programs and curricula on a national level and to revisit the contents and objectives of undergraduate and graduate programs. Furthermore, even Bachelor of Science programs were affected and modified, and changes are still underway. Shortcomings in mathematics are known to be an essential hindrance to young people's interest and success in science and technology. In physics and engineering, at several universities, including Strasbourg, mechanical engineering really suffered from the curricula changes. Fluid mechanics felt to an optional course in undergraduate studies, with a reduced volume of teaching hours. Even main courses such as "Mathematical Methods for Physicists" had to be revisited. Almost every year, teachers like me had to scale down our ambitions in terms of the contents of our courses in linear algebra, analysis, computer science, and applied mathematics, as well as gradually adapt the learning and teaching level to meet students' lower competencies in scientific knowledge, especially in basic mathematics. Under these unforeseen circumstances, teaching methods, skill evaluation, and curricula content must be continuously adjusted.

\subsection{Case of Undergraduate Students}

The curricula contents for undergraduate students have been progressively reduced to statics of fluids, simple viscous flows, flows in pipes and open channels, and flows around immersed bodies. For instance, the solution of Stokes' creeping flow field around a sphere at a very small Reynolds number is no longer calculated mathematically. The first and second Stokes' problems (flow over a suddenly accelerated plate, flow above an oscillating infinite plate) and unsteady Couette flow between parallel plates are no longer addressed analytically, due to insufficient abilities in mathematics. Misconceptions about the ideal gas law, fluid statics, Bernoulli's equation, and Archimedes' principle are frequently observed in undergraduate students. Confusion between relative density or specific gravity (in hydraulics 1 for water) and volume weight or density $\left(1000 \mathrm{~kg} / \mathrm{m}^{3}\right.$ for water), as well as between kinematic and dynamic viscosity, is not uncommon. More worrying is that students are unable to write down the volume of a sphere $V=4 \pi R^{3} / 3$ or the surface of a disk $S=\pi R^{2}$ without the support of an internet connection or a smartphone. Archimedes' buoyancy force is seldom understood, and students think that the buoyancy force increases with depth in water, as is the case with static pressure.

It is the author's opinion that no correlation directly exists between these observations and the Bologna Process, but that they coincide with the generation of 'digital natives' or the 'millennial generation' and indicate that these students approach and structure their studies and everyday life 
in a new way. Reducing the volume of teaching hours and setting the fluid mechanics course as optional did not made things any better in several French universities. The latter change is, however, linked with the reform process. Moreover, reduced financial support has affected the maintenance of experimental equipment and computer equipment.

\subsection{Case of Graduate Students: A Revealing Illustration}

The following short example is one among others that are intended to demonstrate what could be learned by master students only 10 years ago. Many master and PhD students have been working with the author in multiphase flows and particle-laden turbulent flows, on Lagrangian modeling or turbulent dispersion. In Section 2.2.2, the equation of motion of a sphere in a fluid at rest was simplified, including the gravitational, drag, and buoyancy forces. This concept is generally well understood by undergraduate students, even in education sciences:

$$
\frac{\pi}{6} D_{p}^{3} \rho_{p} \frac{d V}{d t}=\frac{\pi D_{p}^{3}}{6}\left(\rho_{p}-\rho_{f}\right) g+\frac{1}{2} C_{d} \frac{\pi D_{p}^{2}}{4} \rho_{f} V^{2}
$$

However, in most cases, the equation is much more complicated and referred to as the Basset-Boussinesq-Oseen (BBO) equation. Thus, the trajectory $X(t)$ of a spherical particle of density $\rho_{p}$, viscosity $v_{f}$, and diameter $D_{p}$, located at $X$ at time $t$, and moving with velocity vector $V(t)$ in a fluid of density $\rho_{f}$ with the fictitious velocity at the center of the particle $U(t)$, is obtained by solving the set of equations

$$
\begin{aligned}
& \frac{\pi}{6} D_{p}^{3}\left(\rho_{p}+C_{a} \rho_{f}\right) \frac{d V}{d t}=-\frac{1}{2} C_{d} \frac{\pi D_{p}^{2}}{4} \rho_{f}|V-U|(V-U)+\frac{\pi D_{p}^{3}}{6} \rho_{f} \frac{D U}{D t} \\
& +C_{a} \frac{\pi D_{p}^{3}}{6} \rho_{f} \frac{d U}{d t}+\frac{\pi D_{p}^{3}}{6}\left(\rho_{p}-\rho_{f}\right) g-C_{h} \frac{D_{p}^{2}}{4} \rho_{f}\left(\pi v_{f}\right)^{\frac{1}{2}} \int_{0}^{t} \frac{d}{d \tau}(V-U) \frac{d \tau}{\sqrt{t-\tau}} \\
& \frac{d X(t)}{d t}=V(t) \text { with } \frac{d}{d t}=\left(\frac{\partial}{\partial t}+V_{j} \frac{\partial}{\partial x_{j}}\right) \text { and } \frac{D}{D t}=\left(\frac{\partial}{\partial t}+U_{j} \frac{\partial}{\partial x_{j}}\right)
\end{aligned}
$$

where $C_{d}$ is the drag coefficient, $C_{a}$ the added mass coefficient, $C_{h}$ the Basset history term coefficient, and the particle Reynolds number is based on the particle-fluid slip velocity $|V-U|$. Master's and even $\mathrm{PhD}$ students in mechanical engineering now have real difficulty in understanding and handling this type of equation, not to mention solving it numerically. Adding a Magnus force (and torque equation) is even more complicated for them.

Working with Generation Y, another term designating the digital natives, has some positive returns on learning and teaching in general. Teachers have to change their pedagogical methods, switching from self-centered teaching to a student-centered learning environment. They have to question their own teaching techniques and find strategies to stimulate the students' interests. Insofar as the author had the possibility to get involved in education sciences over the past 10 years, it made sense to him to join the teaching and learning committee of the French Mechanics Association in order to foster education in fluid mechanics.

\section{Fluid Mechanics Remediation Test}

The French Mechanics Association, regrouping many academic university members as well as industrial companies, has a committee (GTT-AUM) working on the subject of learning and teaching mechanics at university. One of their aims is to develop tests for students that enable them to summarize their knowledge in different fields (Newton's laws, solid statics, fluid mechanics, etc.). A further the idea is to propose simple tools of remediation to students and university instructors, consisting of course refreshers to go over basic concepts, exercises, videos, and simple experiments. In the past six years, the commission has investigated concept inventories (CI) that have been well implemented in North America. The lack of interest in science and technology, as well as in mathematics, among 
young people profoundly affects the mechanical engineering sector. Instructors are aware of the need to revitalize traditional education and rethink pedagogical strategies.

\subsection{Conceptual vs. Procedural Knowledge, Misconceptions}

Conceptual knowledge, as defined by Rittle-Johnson and Wagner-Alibali [33], is an "explicit and implicit understanding of the principles that govern a domain and of the interrelations between pieces of knowledge in a domain". Other complementary definitions exist [34-36]. In contrast, procedural knowledge is defined as "action sequences for solving problems" [37]. Conceptual knowledge plays a key role in solving engineering problems. Learning science is not a rote memorization of figures, facts, laws, equations, and experimental or computational procedures. Teachers have to develop learning strategies and apply innovative pedagogies to guide students to acquire knowledge, add knowledge of new concepts, fill gaps, and avoid misconceptions [38-40].

\subsection{Concept Inventories (CI)}

Concept inventories are designed to be efficient tools in physics and engineering education and have been developed to identify key student misconceptions. They "are research-based assessment instruments that probe students' understanding of particular physics concepts" [41]. They use multiple-choice questions (MCQs) on the topic of one or a set of concepts. They have multiple-choice answers including distractor answers (incorrect choices) that ideally match misconceptions [42]. Moreover, they are resources for teaching evolution [43]. They are used as pre-tests to assess students' prior knowledge and as post-tests at the end of courses to estimate the changes in students' conceptual understanding. They originated in physics education research (PER) and became popular as efficient tools in engineering education for capturing conceptual understanding. They are rather carefully designed, multiple-choice instruments that require students to select the correct answer for a particular problem among distractors based on known student misconceptions.

In the 1980s, Halloun and Hestenes [44,45] developed a "multiple-choice mechanics diagnostic test" to assess students' concepts about motion. They later developed a force concept inventory (CI) and a basic mechanical test (BMT) based on Newton's laws. The FCI, a test of conceptual understanding of the three Newton's laws in mechanics, was further improved [46] and is now widely used as a reference, a so-called 'gold standard' conceptual inventory in the physical sciences. It consists of $30 \mathrm{MCQs}$ with five answer choices (including distractors) for each question and is effective in testing students' understanding of the mechanical concepts of force, motion, velocity, and acceleration of Newton's three laws. It has been administered to thousands of physics students worldwide and is a strong indicator of misconceptions. In addition to the famous force concept inventory (FCI), the Foundation Coalition (FC), funded by the National Science Foundation (NSF), has introduced a variety of assessments for specific discipline domains within engineering and created resources and development projects for partner campuses. The development of CIs is one objective [47]. Members of the Foundation Coalition have introduced a variety of assessments for domains within engineering, including electronic circuits, signals and systems, fluid mechanics, acoustics, waves, computer engineering, electromagnetics, dynamics, civil engineering, heat transfer, thermodynamics, and material science.

\subsection{The American Fluid Mechanics Concept Inventory (FMCI)}

Among the many tests developed for engineering and physics education in the United States [48-55], one is devoted to fluid mechanics [5,6]. Initiated by a cooperative effort between Jay Martin and John Mitchell at the University of Wisconsin-Madison and Ty Newell at the University of Illinois, Champaign-Urbana in 2001, it led to a final version in 2006 with the aim of promoting student understanding of fluid mechanics, as taught in mechanical engineering in the United States. The purpose of these inventories is to check whether fundamental concepts are understood by students, without any calculations. The results of the FMCI test are intended to modify and improve the way fluid mechanics courses are taught. 
Like the FCI, it consists of 30 MCQs including graphics with five answer choices for each question, and it tests student understanding of disparate concepts in fluid mechanics, with no numerical calculation being necessary. Watson et al. [56] recently proposed to modify the FMCI test for civil engineers. They started by regrouping the main concepts for each question. Table 2 summarizes the different concepts. Many distracters in the test items embody commonsense beliefs about the nature of force and its effect on motion.

Table 2. Concepts tested on the existing American Fluid Mechanics Concept Inventory (FMCI) [56].

\begin{tabular}{ll}
\hline & Targeted Concepts \\
\hline 3 Continuity; compressible & 18 Manometry; compressible \\
4 Bernoulli; incompressible & 19 Drag force; compressible \\
5 Boundary conditions & 20 Boundary layer; compressible \\
6 Momentum; incompressible & 21 Boundary layer; incompressible \\
7 Pressure definition & 22 Continuity; incompressible \\
8 Boundary layers; incompressible & 23 Continuity/Bernoulli; incompressible \\
9 Pascal's Law & 24 Boundary layer; compressible \\
10 Manometry; compressible & 25 Impulse-momentum; incompressible \\
11 Bernoulli; incompressible & 26 Boundary layer; compressible \\
12 Forces on submerged surface & 27 Continuity/Bernoulli; incompressible \\
13 Ideal Gas Law & 28 Drag force; compressible \\
14 Manometry; compressible & 29 Drag force; compressible \\
15 Shear stress; compressible & 30 Pressure measurement; compressible \\
16 Boundary layers & 31 Continuity/Temperature variations; compressible \\
17 Bernoulli; incompressible & 32 Fluid properties (viscosity) \\
\hline
\end{tabular}

To get an idea of the FMCI, a specific example of a multiple-choice question (question 1 of the FMCI) is given by Martin et al. [6] for a compressible flow in a pipe of constant section, with the downstream density being half of the upstream density. Answers concern the relationship between the up- and downstream velocities. Distractor answers state that the velocity would be smaller too, and both factor 2 and 4 are proposed. Wrong answers are typical for mass flux misinterpretations.

Another example developed in [57] refers to the flow of liquids in a contraction; a common misconception claims that the greater the velocity is, the greater the pressure will be. Several studies indicate that, for students, either liquids are compressible or pressure is a force and force is linked to velocity and not to acceleration, a typical misconception in the FCI. Here, Bernoulli's equation was clearly not understood.

Based on the last draft of the FMCI (version 3.4) from John Mitchell in 2016, a French version was written with small modifications and issued in January 2019. The previous concept table was modified (Table 3) and the questions were classified into four groups:

- $\quad$ Statics of fluids, seven questions (Q7, Q9, Q10, Q12, Q14, Q18, Q30);

- Ideal fluids and conservation laws (Bernouilli, Euler), 10 questions (Q3, Q4, Q6, Q13, Q17, Q22, Q23, Q25, Q27, Q31);

- $\quad$ External viscous flows, seven questions (Q5, Q19, Q20, Q24, Q26, Q28, Q29);

- Internal viscous flows, six questions (Q8, Q11, Q15, Q16, Q21, Q32).

The present classification was optimized according to the French curricula in in higher education institutions. Remediation tools (complementary lecture notes and numerous exercises with solutions) were recently implemented on a Moodle platform. The French and English FMCI will be tested in several French university classrooms this autumn and winter. Following this, the results will have to be processed. 
Table 3. Concepts revisited for the French FMCI test (version VF1-2019).

\begin{tabular}{ll}
\hline & Targeted Concepts \\
\hline & 19 Laminar drag force over a flat-plate \\
3 Continuity; compressible & 20 Boundary layer; control volume approach \\
4 Bernoulli; incompressible & 21 Flow between two moving flate-plates, velocity \\
5 Boundary conditions for boundary layer & profile \\
6 Momentum; incompressible, Euler & 22 Continuity; incompressible \\
7 Pressure definition, statics & 23 Continuity/Bernoulli; vertical diffuser, \\
8 Viscous flow between flat-plates; incompressible & incompressible \\
9 Pascal's Law, statics & 24 Boundary layer; velocity profile \\
10 Manometry; compressible, Bernoulli & 25 Impulse-momentum; incompressible \\
11 generalized Bernoulli; pressure loss in pipes & 26 Boundary layer and wall stress profile \\
12 Forces on submerged surface & 27 Continuity/Bernoulli; vertical contraction, \\
13 Ideal Gas Law & incompressible \\
14 Manometry; statics & 28 Drag force of different profiles in air \\
15 Shear stress & 29 Drag force; viscous drag \\
16 Flow between two flat-plates, velocity profile & 30 Pressure measurement; Prandtl/Pitot tube \\
17 Bernoulli; flow in a horizontal diffuser & 31 Continuity/Temperature variations; compressible \\
18 Manometry; compressible, statics & flow through a diffuser \\
& 32 Fluid properties (viscosity) \\
\hline
\end{tabular}

The FMCI will certainly be revisited after expertise and results processing, as well as the collection of instructor and student feedback. Several versions could emerge due to the numerous concepts in fluid mechanics; they will have to fit the level (undergraduate or graduate) and the scientific engineering field (mechanical, civil, chemical engineering, hydrodynamics, aerodynamics). Currently, no question concerns open-channel flows, supersonic flows, instabilities, or turbulence. Only one question refers to pipe flows.

\section{Work in Progress in Learning and Teaching Fluid Mechanics}

A personal objective of the author, in collaboration with a young colleague, is to split the FMCI and provide several new versions of the FMCI-an ambitious project. For undergraduates, the versions would concern statics and ideal flows, then viscous flows, last compressible flows, and aerodynamics. For graduates, the versions would address turbulence, multiphase flows (according to textbooks like that of Clayton Crowe from Washington State University), and last numerical methods in fluids. In our Faculty of Physics and Engineering, for the 2019/2020 autumn/winter semester, undergraduate students will be FMCI-tested twice, at the beginning and at the end of the fluid mechanics course. Furthermore, a specific multiple-choice question test of 15 questions on statics and ideal fluid flow will be created for formative assessment. At the same time, MCQs will be created for our Master's students concerning numerical methods in fluid flow (CFD—Computation Fluid Dynamics). Last, students will be required to anonymously complete a teaching evaluation form, specific to the course, in addition to the standard assessment proposed by the faculty. These measures will hopefully help our professional development.

As a potential tutor of the young colleague for the coming year, the author has the will to implement a student-centered teaching, also referred to as learner-centered teaching. The idea is to take inspiration from flipped classrooms, as well as active and cooperative learning strategies. To reinforce these beliefs, a summary of more general own opinions and presently explored topics related to the recent literature is given here. It concerns education sciences applied to engineering and fluid mechanics, and more generally to science, technology, engineering, and mathematics (STEM).

In college learning, the replacement of true experiments by virtual experiments and numerical simulations was certainly a wrong choice for many university engineering science programs. True experimental work based on the use of experimental equipment, and measurement techniques are an invaluable step to really understand the physics and mechanisms of causal processes and predict phenomena. Establishing cause and effect relations is a key principle in a scientific approach. In fluid 
mechanics, experimental investigations have always fostered theoretical studies, modelling and more recently complex numerical simulations. Relevant examples are experiments conducted in the space station science NASA programs in microgravity on microfluidics, Maragoni effects among others. Unfortunately, experimental equipment and maintenance are expensive, much more than a computer room and software dedicated to numerical simulations, and must also be equipped with computers for data processing.

New assessment tools, skill assessments, and concept inventories certainly have to be reviewed and optimized. Thus, the use of student interviews can help the development of so-called FASI-type teaching instruments (FASI-Formative Assessment of Instruction) and to measure student learning, expert-like thinking, and the effectiveness of instruction [58], rather than only employing a summative assessment of student learning. It is also necessary to understand what we are assessing, by using newly developed tools such as concept inventories, three-dimensional learning (3DL), and 3DLAPs (3D learning assessment protocols) [58,59].

Even the physics of ideal fluids has revealed misconceptions, and difficulties encountered by students in classical hydrodynamics (Bernoulli's equation) have been reported in detail [57]. This paper corroborates several misconceptions on pressure and velocity in ideal fluids and naive interpretations of Bernoulli's equation, and includes a valuable (though incomplete) bibliography.

In fluid mechanics, literature on teaching, formative assessment, remedial instruction, and tools are expanding much more than excepted. It has been reported that concepts from pressure and fluid statics [57,60-65], to Archimedes' principle [66], to Bernoulli's law often lead to misunderstandings [67-72]. To combat such misconceptions, various studies have developed approaches such as CFD instrumentation, e-learning, experimental hands-on implementation, interview analyses, student engagement, and interactive learning techniques, among others [73-80]. New instructional methods have been developed in the past 10 years based on active pedagogy [81], problem-based approaches [82], real-world problems, and flipping classes [83-86]. Societal changes and students' needs and demands request both a richer and more efficient learning environment, necessitating adjustments in teaching. In France, serious research on educational sciences, related to learning and teaching in Universities, started late after 2008, in the field of fluid mechanics and more generally in mechanics.

Educational research and physics education research (PER) must offer guidance on how students should think and learn, and on how we can develop true assessments and coherent curricula in physics and fluid mechanics in order to promote the emergence of innovative teaching techniques and to incite interest in science from audiences of all ages (from childhood to higher education). Several handbooks have been published recently on science learning and teaching research [87-90]; on evidence-based e-learning design [91]; on cognition and metacognition in science, technology, engineering, and mathematics (STEM) [89]; and on hands-on methods to improve education at the elementary, secondary, and collegiate levels [91]. There is no doubt that promoting science interest in primary and secondary education will give the necessary impetus to enhancing student contribution and participatory learning. Science laboratory exercises are fundamental. Over the past 20 years, collaborative, cooperative, peer-instruction/learning/teaching, problem-based, project-based learning and teaching have been promoted. These concepts can be seen as extensions of hands-on and inquiry-based activities, aligning well with other teaching methods such as ICT (Information and Communication Technology)-supporting approaches. Moreover, self-, peer-, and group-assessments are being explored to enhance the quality of teaching and learning in higher education. Fluid mechanics, a rather complex science that is necessarily connected to other engineering fields such as thermal science and chemical and computer engineering, is perfectly suited to reinvigorate and foster students' curiosity and knowledge if such methods are further developed. 


\section{Conclusions}

Personal investment in teaching fluid mechanics over 40 years in France has brought satisfaction in different areas. In mechanical engineering, undergraduate and graduate activities have been performed, with enthusiasm, prior to and following the Bologna Process (a reform which sometimes altered the traditional way of teaching and learning) combined with changes in the everyday social life of students. At the same time, more recently, during a period of more than 10 years, a hands-on approach to education was implemented with success for undergraduates wishing to become schoolteachers. The opportunity of learning and teaching this specific method to a younger generation-and the desire to transfer experimental sciences in pupils' classrooms-greatly contributed to the knowledge acquisition of educational sciences and changing teaching methodologies. This also contributed to a desire to develop and implement recently developed tools, derived from the Fluid Mechanics Concept Inventory, which hopefully will help to remove students' misconceptions and misunderstanding of the key concepts in fluid mechanics in some French universities. For the coming years, the challenge will be to apply innovative teaching methods to fluid mechanics, based on a learner-centered teaching approach, in order to foster students' motivation to learn about fluid engineering at Strasbourg University. Furthermore, the proposed teaching evaluations will also hopefully foster the professional development of university teaching staff.

Funding: This research received no external funding.

Acknowledgments: The author expresses his thanks to John Mitchell at the University of Wisconsin-Madison for allowing the use of FMCI in French higher education institutions. The present paper is dedicated to Henri Burnage (1935-2018), from Strasbourg University and to Emeritus Barry Bernstein (1930-2014), from the Illinois Institute of Technology.

Conflicts of Interest: The author declare no conflict of interest.

\section{References}

1. Flick, L.B. The Meanings of Hands-On Science. J. Sci. Teach. Educ. 1993, 4, 1-8. [CrossRef]

2. Sorbonne Declaration. Available online: http://www.ehea.info/cid100203/sorbonne-declaration1998.html (accessed on 15 June 2019).

3. EHEA. The Framework of Qualifications for the European Higher Education Area (PDF). Archived from the Original (PDF) on 23 September 2015. May 2005. Available online: http://www.ehea.info/media.ehea.info/ file/BFUG_Meeting/49/6/BFUG_BG_SR_61_4c_AppendixIII_947496.pdf (accessed on 18 March 2016).

4. McKinney, K. Attitudinal and structural factors contributing to challenges in the work of the scholarship of teaching and learning. New Dir. Inst. Res. 2006, 129, 37-50. [CrossRef]

5. Martin, J.; Mitchell, J.; Newell, T. Development of a Concept Inventory for Fluid Mechanics. In Proceedings of the 33th ASEE/IEE Frontiers in Education Conference, Boulder, CO, USA, 5-8 November 2003; p. 20.

6. Martin, J.K.; Mitchell, J.; Newell, T. Work in Progress: Analysis of Reliability of the Fluid Mechanics Concept Inventory. In Proceedings of the 34th ASEE/IEEE Frontiers in Education Conference, Savannah, GA, USA, 20-23 October 2004.

7. New Approach to Science Teaching Needed in Europe, Say Experts. Available online: http://europa.eu/rapid/ press-release_IP-07-797_en.htm?locale=en (accessed on 15 June 2019).

8. Caltech Mourns Professor Emeritus Jerry Pine. Available online: https://www.caltech.edu/about/news/ caltech-mourns-professor-emeritus-jerry-pine-80363 (accessed on 28 June 2019).

9. Popper, K. Conjectures and Refutations: The Growth of Scientific Knowledge, 5th ed.; Routledge: London, UK, 1989.

10. Popper, K. Objective Knowledge: An Evolutionary Approached, Revised Edition; Oxford University Press: Oxford, UK, 1979; p. 30.

11. Popper, K.R. The Logic of Scientific Discovery; Hutchinson \& CO: London, UK, 1959.

12. Lawson, A.E. The generality of hypothetico-deductive reasoning: Making scientific thinking explicit. Am. Biol. Teach. 2000, 62, 482-495. [CrossRef]

13. Lewis, R.W. Biology: A hypothetico-deductive science. Am. Biol. Teach. 1988, 50, 362-366. [CrossRef] 
14. Available online: http://daniel-huilier.fr (accessed on 28 November 2019).

15. The Apollo 15 Hammer-Feather Drop. Available online: https://nssdc.gsfc.nasa.gov/planetary/lunar/apollo_ 15_feather_drop.html (accessed on 3 July 2019).

16. Beard, K.V. Terminal Velocity and Shape of Cloud and Precipitation Drops. J. Atmos. Sci. 1976, 33, 851-864. [CrossRef]

17. Clanet, C.H. Sport ballistics. Annu. Rev. Fluid Mech. 2015, 45, 455-478. [CrossRef]

18. Moreau, R.; Sommeria, J. Traînée subie par les corps en mouvement. Encyclopédie de L'environnement. 2019. Available online: https://encyclopedie-environnement.org (accessed on 28 November 2019).

19. Munson, B.R.; Okiishi, T.H.; Huebsch, W.W.; Rothmayer, A.P. Fundamentals of Fluid Mechanics, 7th ed.; Wiley: Singapore, 2013; Chapter 9.

20. Rott, N. Note on the History of the Reynolds Number 1990. Annu. Rev. Fluid Mech. 1990, 22, 1-12. [CrossRef]

21. Striking Results on Bouncing Balls. Available online: https://staff.fnwi.uva.nl/a.j.p.heck/Research/art/ BouncingBall.pdf (accessed on 25 June 2019).

22. Bouncing Ball Experiment. Available online: https://www.brooklyn.k12.oh.us/userfiles/66/Classes/13814/ Lab\%20-Bouncing\%20Ball.pdf (accessed on 25 June 2019).

23. Hands-on Activity: Reverse Engineering. Available online: https://www.teachengineering.org/activities/ view/ball_bounce_experiment (accessed on 25 June 2019).

24. Schiller, L.; Naumann, Z. VDI Zeitung 1935. Drag Coeff. Correl. 1935, 77, 318-320.

25. Milk Viscosity. Available online: https://www.teachengineering.org/activities/view/nyu_milk_activity1 (accessed on 28 June 2019).

26. Guyon, E.; Hulin, J.P.; Petit, L.; Mitescu, C. Physical Hydrodynamics, 2nd ed.; Oxford University Press: Oxford, UK, 2015.

27. Guyon, É.; Hulin, J.P.; Petit, L. Ce Que Disent Les Fluides, 2nd ed.; Editions Belin: Paris, France, 2011.

28. De Gennes, P.G.; Brochard-Wyart, F.; Quéré, D. Gouttes, Bulles, Perles Et Ondes; Editions Belin: Paris, France, 2002.

29. Batchelor, G. An Introduction to Fluid Dynamics; Cambridge Press University: Cambridge, UK, 2000.

30. Schlichting, H. Boundary Layer Theory, 4th ed.; McGraw-Hill: New York, NY, USA, 1979.

31. Hinze, J.O. Turbulence, 2nd ed.; McGraw-Hill: New York, NY, USA, 1975.

32. Batchelor, G.K. The Scientific Papers of Sir Geoffrey Ingram Taylor; Cambridge Press University: Cambridge, UK, 1960; Volume 2.

33. Rittle-Johnson, B.; Wagner-Alibali, M.W. Conceptual and procedural knowledge of mathematics: Does one lead to the other? J. Educ. Psychol. 1999, 91, 175-189. [CrossRef]

34. Barr, C.; Doyle, M.; Clifford, J.; de Leo, T.; Dubeau, C. There Is More to Math: A Framework for Learning and Math Instruction; Waterloo Catholic District School Board: Waterloo, ON, Canada, 2003.

35. Arslan, S. Traditional instruction of differential equations and conceptual learning. Teach. Math. Appl. Int. J. IMA 2010, 29, 94-107. [CrossRef]

36. Star, J.R. Re-conceptualizing procedural knowledge: The emergence of "intelligent" performances among equation solvers. In Proceedings of the 28th Annual Meeting of the North American Chapter of the International Group for the Psychology of Mathematics Education, Columbus, OH, USA, 26-29 October 2002; Mewborn, D., Sztajn, P., White, D., Wiegel, H., Bryant, R., Nooney, K., Eds.; ERIC Clearinghouse for Science, Mathematics, and Environmental Education: Columbus, OH, USA, 2002; pp. 999-1007.

37. Rittle-Johnson, B.; Siegler, R. The relations between conceptual and procedural knowledge in learning mathematics: A review, chapter 4. In Studies in Developmental Psychology. The Development of Mathematical Skills; Donlan, C., Ed.; Psychology Press: Hove, UK; Taylor \& Francis: London, UK, 1998; pp. 75-110.

38. Rittle-Johnson, B. Promoting transfer: Effects of self-explanation and direct instruction. Child Dev. 2006, 77, 1-15. [CrossRef] [PubMed]

39. Piaget, J.; Cook, M.; Norton, W. The Origins of Intelligence in Children; International Universities Press: New York, NY, USA, 1952; Volume 8.

40. Chi, M.T.; Slotta, J.D.; de Leeuw, N. From things to processes: A theory of conceptual change for learning science concepts. Learn. Instr. 1994, 4, 27-43. [CrossRef] 
41. Madsen, A.; McKagan, S.; Sayre, E. Best Practices for Administering Concept Inventories. Phys. Teach. 2017, 55, 530. [CrossRef]

42. Sadler, P.M. Psychometric models of student conceptions in science: Reconciling qualitative studies and distractor-driven assessment instruments. J. Res. Sci. Teach. 1998, 35, 265-296. [CrossRef]

43. Furrow, R.E.; Hsu, J.L. Concept inventories as a resource for teaching evolution. Evol. Educ. Outreach 2019, 12, 11. [CrossRef]

44. Halloun, I.A.; Hestenes, D. The initial knowledge state of college physics students. Am. J. Phys. 1985, 53, 1043-1055. [CrossRef]

45. Halloun, I.A.; Hestenes, D. Common sense concepts about motion. Am. J. Phys. 1985, 53, $1056-1065$. [CrossRef]

46. Hestenes, M.; Wells, G. Swackhamer, Force Concept Inventory. Phys. Teach. 1992, 30, 141-158. [CrossRef]

47. Coalition Foundation. Available online: http://fc.civil.tamu.edu/ (accessed on 25 June 2019).

48. Lindell, R.S.; Peak, E.; Foster, T.M. Are They All Created Equal? A Comparison of Different Concept Inventory Development Methodologies. In AIP Conference Proceedings 883; McCullough, L., Heron, P., Hsu, L., Eds.; AIP Press: Melville, NY, USA, 2007; pp. 14-17. [CrossRef]

49. Adams, W.K.; Wieman, C.E. Development and Validation of Instruments to Measure Learning of Expert-Like Thinking. Int. J. Sci. Educ. 2011, 33, 1289-1312. [CrossRef]

50. Available online: www.physport.org/assessments (accessed on 7 July 2019).

51. Henderson, C. Common Concerns about the Force Concept Inventory. Phys. Teach. 2002, 40, 542. [CrossRef]

52. Laverty, J.T.; Caballero, M.D. Analysis of the most common concept inventories in physics: What are we assessing? Phys. Rev. Phys. Educ. Res. 2018, 14, 010123. [CrossRef]

53. Gray, G.L.; Evans, D.; Cornwell, P.; Costanzo, F.; Self, B. Toward a nationwide dynamics concept inventory assessment test. In Proceedings of the American Society for Engineering Education Annual Conference \& Exposition, Nashville, TN, USA, 22-25 June 2003.

54. List of Concept Inventories. Available online: http:/fc.civil.tamu.edu/home/keycomponents/concept/index. html (accessed on 28 June 2019).

55. David Sands, D.; Parker, M.; Hedgeland, H.; Jordan, S.; Galloway, R. Using concept inventories to measure understanding. High. Educ. Pedagog. 2018, 3, 173-182. [CrossRef]

56. Watson, K.; Mills, R.; Bower, K.; Brannan, K.; Woo, M.; Welch, R. Revising a Concept Inventory to Assess Conceptual Understanding in Civil Engineering Fluid Mechanics. In Proceedings of the 122nd ASEE Annual Conference \& Exhibition, Seattle, WA, USA, 14-16 June 2015.

57. Suarez, A.; Kahan, S.; Zavala, G.; Marti, A.C. Student Conceptual Difficulties in Hydrodynamics. Phys. Rev. Phys. Educ. Res. 2017, 13, 020132. [CrossRef]

58. Laverty, J.T.; Underwood, S.M.; Matz, R.L.; Posey, L.A.; Carmel, J.H.; Caballero, M.D.; Fata-Hartley, C.L.; Ebert-May, D.; Jardeleza, S.E.; Cooper, M.M. Characterizing College Science Assessments: The ThreeDimensional Learning Assessment Protocol. PLoS ONE 2016, 11, e0162333. [CrossRef]

59. National Research Council. A Framework for K-12 Science Education; The National Academies Press: Washington, DC, USA, 2012. [CrossRef]

60. Besson, U. Students' conceptions of fluids. Int. J. Sci. Educ. 2004, 26, 1683-1714. [CrossRef]

61. Loverude, M.E.; Heron, P.R.L.; Kautz, C.H. Identifying and addressing student difficulties with hydrostatic pressure. Am. J. Phys. 2010, 78, 75-85. [CrossRef]

62. Matewsky, M.; Boyer, A.; Bazan, Z.; Wagner, D.J. Exploring student difficulties with pressure in a fluid. AIP Conf. Proc. 2013, 1513, 154-157.

63. Nihous, G.C. Notes on hydrostatic pressure. J. Ocean Eng. Mar. Energy 2016, 2, 105-109. [CrossRef]

64. Young, D.; Meredith, D.C. Using the resources framework to design, assess, and refine interventions on pressure in fluids. Phys. Rev. Phys. Educ. Res. 2017, 13, 010125. [CrossRef]

65. Koumaras, P.; Pierratos, T.H. How Much Does a Half-Kilogram of Water "Weigh"? Phys. Teach. 2015, 53, 174-176. [CrossRef]

66. Loverude, M.E.; Kautz, C.H.; Heron, P.R. Helping students develop an understanding of Archimedes' principle. I. Research on student understanding. Am. J. Phys. 2003, 71, 1178-1187. [CrossRef] 
67. Recktenberg, G.W.; Edwards, R.C.; Howe, D.; Faulkner, J. Simple Experiment to Expose Misconceptions about the Bernoulli Equation. In Proceedings of the ASME 2009 International Mechanical Engineering Congress and Exposition, Lake Buena Vista, FL, USA, 13-19 November 2009; Volume 7, pp. 151-160. [CrossRef]

68. Bedford, D.; Lindsay, R. A misinterpretation of Bernoulli's theorem. Phys. Educ. 1977, 12, 311-312. [CrossRef]

69. Eastwell, P. Bernoulli? Perhaps but What about Viscosity? Sci. Educ. Rev. 2007, 6, 1-13.

70. Eastwell, P. Thinking Some More about Bernoulli. Phys. Teach. 2008, 46, 555-556. [CrossRef]

71. Kamela, M. Thinking about Bernoulli. Phys. Teach. 2007, 45, 379-381. [CrossRef]

72. Martin, D.H. Misunderstanding Bernoulli. Phys. Teach. 1983, 21, 37. [CrossRef]

73. Kusairi, S.; Alfad, H.; Zulaikah, S. Development of Web-Based intelligent (iTutor) to help students learn fluid statics. J. Turkish Sci. Educ. 2017, 14, 1-11. [CrossRef]

74. Fraser, D.M.; Pillay, R.; Tjatindi, L.; Case, J.M. Enhancing the Learning of Fluid Mechanics Using Computer Simulations. J. Eng. Educ. 2007, 96, 279-289. [CrossRef]

75. Stern, F.; Xing, T.; Yarbrough, D.B.; Rothmayer, A.; Rajagopalan, G.; Prakashotta, S.; Caughey, D.; Bhaskaran, R.; Smith SHutchings, B.; Moeyke, S. Hands-On CFD Educational Interface for Engineering Courses and Laboratories. J. Eng. Educ. 2006, 95, 63-83. [CrossRef]

76. Cranston, G.; Lock, G. Techniques to encourage interactive student learning in a laboratory setting. Eng. Educ. 2012, 7, 2-10. [CrossRef]

77. Lu, H.; Zhang, X.; Jiang, D.; Zhao, Z.; Wang, J.; Liu, J. Several Proposals to Improve the Teaching Effect of Fluid Mechanics. In Emerging Computation and Information Chnologies for Education. Advances in Intelligent and Soft Computing; Mao, E., Xu, L., Tian, W., Eds.; Springer: Berlin/Heidelberg, Germany, 2012; Volume 146. [CrossRef]

78. Burgher, J.; Finkel, D.; van Wie, B.J.; Adescope, O.O. Comparing misconceptions in fluid mechanics using interview analysis pre and post hands-on learning module treatment. In Proceedings of the 121st ASEE Annual Conference \& Exposition, Indianapolis, IN, USA, 15-18 June 2014.

79. Brown, A. Enhancing learning of fluid mechanics using automated feedback and by engaging students as partners. In Proceedings of the Higher Education Academy Annual Conference, Birmingham, UK, 2-3 July 2014; p. 2.

80. Albers, L.; Bottomley, L. The Impact of Activity Based Learning, A New Instructional Method, In an Existing Mechanical Engineering Curriculum for Fluid Mechanics. In Proceedings of the 118th ASEE Annual Conference \& Exposition, Vancouver, BC, Canada, 26-29 June 2011; Available online: https: //www.asee.org/public/conferences/1/papers/781/view (accessed on 25 June 2019).

81. Bondehagen, D.L. Inspiring students to learn fluid mechanics through engagement with real world problems. In Proceedings of the 118th ASEE Annual Conference \& Exposition, Vancouver, BC, Canada, 26-29 June 2011; Available online: https://peer.asee.org/18190 (accessed on 24 June 2019).

82. McClelland, C.J. Flipping a large-enrollment fluid mechanics course-Is it effective? In Proceedings of the 120th ASEE Annual Conference \& Exposition, Atlanta, GA, USA, 23 June 2013; Available online: https://www.asee.org/public/conferences/20/papers/7911/view (accessed on 24 June 2019).

83. Webster, D.R.; Majerich, D.M.; Madden, A. Flippin'Fluid Mechanics-Comparison Using Two Groups. Adv. Eng. Educ. 2016, 5, 1-20.

84. Webster, D.R.; Majerich, D.M.; Luo, J. Flippin' Fluid Mechanics-Quasi-experimental Pre-test and Post-test Comparison Using Two Groups. In Proceedings of the DFD14 Meeting of The American Physical Society, San Francisco, CA, USA, 23-25 November 2014.

85. Wachs, F.L.; Fuqua, J.L.; Nissenson, P.M.; Shih, A.C.; Ramirez, M.P.; DaSilva, L.Q.; Nguyen, N.; Romero, C. Successfully Flipping a Fluid Mechanics Course Using Video Tutorials and Active Learning Strategies: Implementation and Assessment? In Proceedings of the 125th ASEE Annual Conference \& Exhibition, Salt Lake City, UT, USA, 24-27 June 2018; Available online: https://www.asee.org/public/conferences/106/papers/ 23046/view (accessed on 8 July 2019).

86. Pietrocola, M. Upgrading Physics Education to Meet the Needs of Society; Springer: Berlin/Heidelberg, Germany, 2019.

87. Kalman, C.S. Successful Science and Engineering Teaching: Theoretical and Learning Perspectives; Springer International Publishing: Cham, Switzerland, 2018.

88. Dori, Y.J.; Mevarech, Z.R.; Baker, D.R. Cognition, Metacognition and Culture in STEM Education: Leraning, Teaching and Assessment; Springer international Publishing: Cham, Switzerland, 2018. 
89. Pietrocola, M.; Gurgel, I. Crossing the Border of the Traditional Science Curriculum: Innovative Teaching in Basic Science; Sense Publishers: Rotterdam, The Netherlands, 2017.

90. Clark, R.C.; Mayer, R.E. E-Learning and the Science of Instruction: Proven Guideline for Consumers and Designers of Multimedia Learning; Wiley: Hoboken, NJ, USA, 2016.

91. De Silva, E. Cases on Research-Based Teaching Methods in Science Education; IGI Global: Hershey, PA, USA, 2014.

(C) 2019 by the author. Licensee MDPI, Basel, Switzerland. This article is an open access article distributed under the terms and conditions of the Creative Commons Attribution (CC BY) license (http://creativecommons.org/licenses/by/4.0/). 